\title{
Inter- and intraspecific variability of plant individual growth and its role on species ranking in grasslands
}

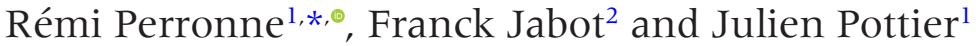 \\ ${ }^{1}$ UCA, INRAE, VetAgro Sup, UMR Ecosystème Prairial, site de Crouel, 5 chemin de Beaulieu, F-63000 Clermont-Ferrand, France, ${ }^{2}$ UCA, \\ INRAE, UR LISC, Centre de Clermont-Ferrand, 9 avenue Blaise Pascal, F-63178 Aubière, France
}

*Corresponding author. E-mail: remi.perronne@inrae.fr

Handling Editor: Qing Ye

Received: 16 December 2019, Revised: 3 March 2020, Accepted: 21 May 2020, Advanced Access publication: 27 May 2020

Citation: Perronne R, Jabot F, Pottier J (2020) Inter- and intraspecific variability of plant individual growth and its role on species ranking in grasslands. J Plant Ecol 13:378-386. https://doi.org/10.1093/jpe/rtaa021

\begin{abstract}
Aims Individual growth constitutes a major component of individual fitness. However, measuring growth rates of herbaceous plants nondestructively at the individual level is notoriously difficult. This study, based on an accurate non-destructive method of aboveground biomass estimation, aims to assess individual relative growth rates (RGRs) of some species, identify its environmental drivers and test its consequences on community patterning. We specifically address three questions: (i) to what extent environmental conditions explain differences in individual plant growth between sites, (ii) what is the magnitude of intraspecific variability of plant individual growth within and between sites and (iii) do species-averaged (dis-)advantage of individual growth compared with the whole vegetation within a site correlate with species ranking at the community level?

Methods We monitored the growth of individuals of four common perennial species in 18 permanent grasslands chosen along a large pedoclimatic gradient located in the Massif Central, France. We measured soil properties, levels of resources and meteorological parameters to characterize environmental conditions at the site level. This design enables us to assess the influence of environmental conditions on individual growth and the relative extent of inter-individual variability of growth explained within and between sites. We determined the ranking of each of the four species in each site with botanical surveys to assess the relationship between species-averaged growth (dis-) advantage relative to the whole community and species rank in the community.

Important Findings We found that environmental conditions explain a significant proportion of individual growth variability, and that this proportion is strongly variable between species. Light availability was the main driver of plant growth, followed by rainfall amount and potential evapotranspiration, while soil properties had only a slight effect. We further highlighted a moderate to high within-site interindividual variability of growth. We finally showed that there was no correlation between species ranking and species-averaged individual growth.
\end{abstract}

Keywords: relative growth rate, species ranking, non-destructive biomass estimation, temperate permanent grasslands, inter-individual variability

摘要: 植物个体的生长是其适合度的重要组成部分。然而, 在个体水平上非破坏性地测量草本植物的生长速度非常困难。本研究基于准确 的非破坏性地面生物量估算方法, 旨在评估某些物种的个体相对生长速率, 识别其环境驱动因子, 并检验其对群落模式的影响。我们提出 以下三个具体的科学问题: (1)环境条件可以在多大程度上解释个体植物生长在不同样地间的差异; (2)在相同样地内和不同样地间, 植物个 体生长的种内差异有多大, 以及(3)相同样地内, 平均每个物种的个体生长相较于整个植被的优势/劣势, 与群落水平的物种等级是否有关? 为了回答上述问题, 我们在法国中央高地沿古气候梯度的 18 个永久草地内监测了 4 种常见的多年生植物的个体生长。我们测量了土壤性质、 资源水平和气象参数, 以表征样地的环境条件。这使我们能够评估环境条件对个体生长的影响, 以及在相同和不同样地之间个体间生长变 异的相对程度。我们通过植物学调查确定了每个样地内四个物种的等级, 以评估物种平均个体生长相对于整个群落的优势/劣势与物种在群 落中的等级之间的关系。研究结果表明, 环境条件解释了个体生长变异性很重要的一部分, 而且这部分变异在物种之间也有很大差异。光 
照有效性是影响植物生长的主要因素, 其次是降雨量和潜在的蒸散量, 而土壤性质对植物生长的影响较小。我们的结果进一步强调了相同 样地内个体间生长变异的程度是中到高, 而且物种等级与物种平均个体生长之间没有相关性。

关键词: 相对生长率, 物种等级, 非破坏性生物量估算, 温带永久草地, 个体间变异

\section{INTRODUCTION}

Species performance has been usually approximated using proxies such as functional traits, i.e. features measurable at the individual level contributing directly or indirectly to fitness (Violle et al. 2007). These functional traits have been successfully related to species ranking at the community level, thereby supporting the assumption that environmental filters may determine community assembly through a species sorting process (e.g. Shipley et al. 2006). In this framework, it is assumed that different species might be favoured and become dominant in different sites given their differential responses in the prevailing environmental conditions (Leibold et al. 2004). Community assembly at local scale is thus considered to be the result of nonrandom demographic processes related to individual fitness and its components, namely survival, growth and reproduction (Violle et al. 2007).

Among the components of individual fitness, growth is considered as a prime determinant of plant ecological strategies (Grime 1977; Reich 2014; Tilman 1988). In particular, the relative growth rate (RGR), thereafter RGR, has been frequently used to summarize plant performance of annual and perennial herbaceous plants in productive habitats (Violle et al. 2007). RGR has been shown to vary at the population level according to changing environmental conditions, such as light and nutrients supply (Altesor et al. 2017; Glimskär and Ericsson 1999; Hofmann and Isselstein 2004; Meziane and Shipley 1999) or herbivory pressure (Rose et al. 2009). Consequently, populationlevel RGR has been used to study the influence of biotic and abiotic environmental filters on community assembly (see e.g. Glimskär and Ericsson 1999; Roscher et al. 2011). However, the relationship between species ranking and RGR has been the subject of only few studies on a limited set of environmental conditions, and showed contradictory results. In hayfield, Epp and Aarssen (1989) found no relationship between growth rate and relative abundance of species at the plot level, while, in infertile abandoned pasture, Reader (1998) highlighted a negative relationship.

Previous studies have analysed the responses and effects of species RGR at the population level because measuring RGR of individual plants is difficult in semi-natural systems, especially for herbaceous perennial species (Rose et al. 2009). Consequently, they did not include inter-individual variability of growth in their analyses. However, the intraspecific variability of numerous functional traits is high, and currently well recognized to play a key role in community assembly (Albert et al. 2010; Siefert et al. 2015). To our knowledge, the interindividual variability of RGR in natural plant communities has not been evaluated so far, although it may have strong consequences on community assembly. Theoretical and empirical studies suggest that inter-individual variability of plant performance and its components may blur interspecific differences in competitive abilities and thus species dominance at the community level (Aarssen and Turkington 1985; Fridley et al. 2007; Uriarte and Menge 2018), although such influence is still debated (Hart et al. 2016; Turcotte and Levine 2016). For instance, in their theoretical model, Uriarte and Menge (2018) especially emphasized that a high inter-individual variability of competitive response can give a disproportionate advantage of the inferior competitor species in spatially heterogeneous habitats. Moreover, Biere (1996) highlighted that the RGR variability influences the competitive ability of a species depending on the environmental conditions experienced. Consequently, there is a need to test whether a high individual growth of a species, mediated by favourable environmental conditions for this species, scale-up to better ranking at the community level, as predicted by the species sorting hypothesis, or whether this could be blurred by large inter-individual variability.

Population-level RGR measurements need cohorts of plants with a comparable initial biomass to carry out destructive measurements. This method cannot de facto focus on the individual level, and thus cannot assess inter-individual variability for herbaceous plants. To overcome this limitation, we use a recently developed method of non-destructive estimation of aboveground biomass allowing repeated measurements on the same individuals (Pottier and Jabot 2017). This method has thus the potential to accurately assess, in temperate grasslands, the growth trajectories of individuals, and is transferable across different environments (Pottier and Jabot 2017).

Using this method, we monitored the spring growth of individual plants of four common species of temperate permanent grasslands distributed along a large pedoclimatic gradient. More specifically, we addressed the three following questions:

(1) To what extent environmental conditions explain differences in individual plant growth between sites? Does their influence vary between species?

(2) How variable is intraspecific variability of plant individual growth within and between sites?

(3) Do species-averaged differences in individual growth within a site correlate with species ranking at the community level?

\section{MATERIALS AND METHODS}

\section{Study sites}

We surveyed 18 temperate permanent grasslands located in the Massif Central, France, from April to July 2017, depending on the altitudinal gradient. Grasslands were chosen in order to include the major pedoclimatic conditions, landscape contexts and management regimes of the study area. Moreover, each site is a permanent grassland characterized by a constant management regime for at least 20 years.

In each selected grassland, a plot of $100 \mathrm{~m}^{2}(10 \mathrm{~m} \times 10 \mathrm{~m})$ was delineated and put under exclosure against large herbivores, mainly cattle, during a period of around 2 months. The period started before the senescence of the first leaf and ended at the biomass peak, thus capturing the peak of growth rate at the community level, between $550 \pm 40$ and $1350 \pm 90$ Growing Degree-Days, thereafter GDD. The GDD allows standardizing phenological stages between the different sites that were distributed along a large climatic gradient. The GDD were calculated following McMaster and Wilhelm (1997) assuming a base temperature of $0^{\circ} \mathrm{C}$ and are accumulated with a starting date at the lst of February. Neither herbage use (mowing or/and grazing) nor nutrient supply were made in these exclosure plots during the period of survey.

\section{Environmental conditions}

Six soil properties were measured at the site level based on standard procedures using a composite soil sample in the $0-20 \mathrm{~cm}$ soil layer: 
soil texture (i.e. clay, silt and sand in \%), $\mathrm{pH}$, total organic carbon (in $\mathrm{g} \mathrm{kg}^{-1}$ ), total nitrogen (in $\mathrm{g} \mathrm{kg}^{-1}$ ), available phosphorous (in $\mathrm{g} \mathrm{kg}^{-1}$ ) and cation exchange capacity. The total organic carbon, total nitrogen and available phosphorous were expressed as total pools within the 0-20 $\mathrm{cm}$ soil layer (in $\mathrm{g} \mathrm{m}^{-2}$ ). Moreover, the maximum plant available water content in the $0-60 \mathrm{~cm}$ soil layer was determined as the difference between soil water content at field capacity and soil water content at wilting point using four non-disturbed soil samples per grassland, and accounting for bulk density and soil depth (available water content, in $\mathrm{mm}$ ). A standardized principal component analysis (PCA) was applied on soil variables to reduce the dimensionality of these data. The main axis of variation of the PCA was retained because most variables are collinear, thereafter soil $\mathrm{PCl}$, and accounts for $58.5 \%$ of the total variance. Soil $\mathrm{PCl}$ summarizes a gradient of potential productivity with positive values associated with sites presenting more resources available (Supplementary Fig. S1).

Three meteorological variables were computed at the site level within the exclosure plot over the period studied: cumulative rainfall $\left(\mathrm{P}_{\text {cumul }}\right.$ in $\left.\mathrm{mm}\right)$, cumulative potential evapotranspiration following the Hargreaves-Samani equation ( $\mathrm{PET}_{\text {cumul }}$ in mm; Hargreaves and Samani 1985) and cumulative photosynthetic active radiation available $\left(\mathrm{PAR}_{\text {cumul' }}\right.$ in $\left.\mathrm{MJ} \mathrm{m}^{-2}\right)$. The dynamic of PAR calculation was made with temporal series of daily global radiations provided by MétéoFrance and field measurements above the canopy and at the ground level to estimate light interception through the plant canopy with a ceptometer. Rainfall, temperature and global radiations were provided by nearest MétéoFrance weather stations. Details of measurements of environmental variables are provided in Supplementary Table S1 and Figure S1.

\section{Growth rate calculation at the individual and the community levels}

We estimated growth rates, at the individual level, for four common perennial species that are typical of permanent grasslands of the Massif Central. The four species were selected from their high frequency in the region of interest according to the atlas of the Auvergne flora (Antonetti et al. 2006). As a result, the four species: Dactylis glomerata, Lolium perenne, Poa pratensis and Trifolium repens were, respectively, observed in 16, 17, 18 and 18 out of 18 sites. These four species are medium- to late-flowering species in the studied sites. Each species can locally be part of the dominant or subordinate species depending on the site. Usually eight plant individuals per species and per site, when the species was present, were marked by a ring surrounding their base. Following the definition of Pottier and Jabot (2017), the term individual is defined as a ramet or collection of clumped ramets with the highest degree of physiological integration. Plant individuals were measured at two periods, $t_{1}(710 \pm 70 \mathrm{GDD})$ and $t_{2}(1350 \pm 90 \mathrm{GDD})$, i.e. the duration of the period between $t_{1}$ and $t_{2}$ was 1 month maximum. Three biometric measurements were recorded: maximum height $(H)$, basal circumference $\left(A_{\text {basal }}\right)$ and circumference at mid height $\left(A_{\text {half }}\right)$. These measurements allowed us to estimate the minimum volume occupied by all aboveground organs of an individual, thus limiting risks of error measurement compared with other available approaches (see Pottier and Jabot 2017 for details). We excluded to rely only on maximum height to assess the aboveground dry biomass of the individuals because this single biometric measurement was found to be clearly outperformed by the minimum volume-based approach (Pottier and Jabot 2017). Based on data and findings of Pottier and Jabot (2017), we rather estimated the aboveground dry biomass of the individuals $\left(W_{\text {ind }}\right)$ as follows (1):

$$
W_{\text {ind }}=1.96\left[\frac{H}{2}\left(A_{\text {basal }}+A_{\text {half }}\right)\right]^{2 / 3}
$$

This general allometric equation showed good predictive accuracy (Normalized Root Mean Square Error [NRMSE] of 0.19), especially for the three species that were part of the analyses performed by Pottier and Jabot (2017), i.e. D. glomerata, L. perenne and P. pratensis $($ NRMSE $=0.17,0.06$ and 0.09 , respectively). Considering the remaining species $T$. repens, we assume equation (1) to be valid because Lotus corniculatus, the species showing the most similar morphology included in Pottier and Jabot (2017), also showed good predictive accuracy (NRMSE $=0.13$, Supplementary Fig. S2). This good predictive accuracy was obtained by considering contrasted sites in terms of altitude, climate, topography, soil type and management regimes in the same biogeographic region, i.e. the Massif Central (see Pottier and Jabot 2017).

This method of non-destructive biomass estimation allowed us to characterize the growth rate of individual plants between the two monitoring dates. We then calculated the RGR of each monitored individual, thereafter $\mathrm{RGR}_{\text {ind' }}$, as follows (2):

$$
\mathrm{RGR}_{\text {ind }}=\frac{\ln \left(W_{2}\right)-\ln \left(W_{1}\right)}{t_{2}-t_{1}}
$$

where $W_{1}$ and $W_{2}$ are the dry aboveground biomass estimation for the individual at the two monitoring dates $t_{1}$ and $t_{2}$ (in GDD).

In order to compare the RGR of plant individuals between sites and relate it to species ranking at the community level, we also characterized RGR at the community level, which corresponds to the specific aboveground net primary productivity-thereafter SANPPdefined by Garnier et al. (2004). The total aboveground biomass was determined at the same two monitoring dates $t_{1}(710 \pm 70 \mathrm{GDD})$ and $t_{2}(1350 \pm 90 \mathrm{GDD})$. The aboveground biomass was clipped at $5 \mathrm{~cm}$ above the ground level from four $0.25-\mathrm{m}^{2}-50 \mathrm{~cm} \times 50 \mathrm{~cm}$-quadrats at the site level. The biomass was then oven-dried for $48 \mathrm{~h}$ at $80^{\circ} \mathrm{C}$, weighed and the aboveground dry biomass per square meter computed as the sum of the four $0.25-\mathrm{m}^{2}$ quadrats. The SANPP was calculated as follows (3):

$$
\text { SANPP }=\frac{\ln \left(B_{2}\right)-\ln \left(B_{1}\right)}{t_{2}-t_{1}}
$$

where $B_{1}$ and $B_{2}$ are the dry aboveground biomass of the whole community (in g), respectively, at the monitoring dates $t_{1}$ and $t_{2}$ (in GDD).

In order to relate plant individual growth of the species to their ranking in the different sites along the pedoclimatic gradient, we propose an indicator of individual growth (dis-)advantage relative to the whole community. This indicator compares relative plant growth to its reference community by dividing the $\mathrm{RGR}_{\text {ind }}$ by the SANPP estimated at the community level. Therefore, $\mathrm{RGR}_{\text {ind }} / \mathrm{SANPP}$ $<$ indicates that the targeted individual has grown slower than the other individuals of co-occurring species which experienced the same site-specific environmental conditions over the growing season. Conversely, $\mathrm{RGR}_{\text {ind }} / \mathrm{SANPP}>1$ indicates that the targeted individual has grown faster than the other co-occurring species.

\section{Botanical survey and community patterns}

To determine the ranking of the four species in each site separately, we conducted botanical surveys at the site level. In each $100-\mathrm{m}^{2}$ plot, a nested sampling design was applied in order to account for potential environmental heterogeneity at different spatial scales. Eight $1-\mathrm{m}^{2}$ quadrats were located regularly within the $100-\mathrm{m}^{2}$ plot. In each quadrat characterized by a $0.1 \mathrm{~m} \times 0.1 \mathrm{~m}$ grid, $100.01-\mathrm{m}^{2}$ mini-quadrats were then randomly chosen. Within each of the $800.01-\mathrm{m}^{2}$ mini-quadrats, we recorded the presence of all co-occurring vascular plant species at the date corresponding to $1060 \pm 90 \mathrm{GDD}$, and we completed this list by taking into account the complementary species observed at the flowering and ripening phenological stages at $550 \pm 40,710 \pm$ 
70 and $1350 \pm 90$ GDD. We characterized the occurrence frequency of each species and the species richness at the scale of the plot. The surveyed temperate permanent grasslands were usually dominated by monocotyledons (from $44.8 \%$ to $71.5 \%$ of the total occurrence frequency observed, on average $57.2 \% \pm 6.6 \%$ ), and characterized by a medium to high species richness (from 32 to 69 species on the 100$\mathrm{m}^{2}$ plot, on average $48 \pm 11$ ), and a relatively high Pielou's evenness $J^{\prime}$ (from 0.73 to 0.84 on the $100-\mathrm{m}^{2}$ plot, on average $0.79 \pm 0.03$; Pielou 1966; see Perronne et al. 2019 for details).

We computed a metric of standardized species ranking as follows (4):

$$
\mathrm{SSR}_{i, s}=1-\frac{\operatorname{rank}_{i, s}}{\text { species } \operatorname{richness}_{s}}
$$

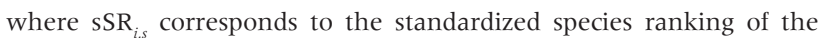
species $i$ at the site $s, \operatorname{rank}_{i, s}$ is the rank of the species $i$ at the site $s$ based on its frequency of occurrence relative to the other species. We divided $\operatorname{rank}_{i, s}$ by the species richness and subtracted the value to 1 in order to have comparable index across sites. Therefore, common species present sSR approaching one and rare species present sSR approaching zero at the site level.

\section{Statistical analyses \\ Sources of variations of individual plant growth}

For each species separately, we assessed the effects of the environmental variables recorded at the site level on the growth of each individual ( $\mathrm{RGR}_{\text {ind }}$ ) using linear mixed models (thereafter LMM). We also accounted for the inter-individual variability of initial size by including the initial aboveground biomass $W_{1}$ measured at the start of the monitoring in the models. Based on Pearson's product-moment correlation tests, no correlation between explanatory variables exceeded 0.7 in absolute value, so all the variables were retained for subsequent analyses (Dormann et al. 2013). A full additive model including the initial aboveground biomass, linear and quadratic effects of the environmental variables (i.e. soil PC1, $\mathrm{P}_{\text {cumul }}$ PET $_{\text {cumul }}$ and $\mathrm{PAR}_{\text {cumul }}$ ) and accounting for the site identity as a random intercept factor, was compared with all other simpler additive models (i.e. including only a subset of the environmental variables) based on the second-order Akaike information criterion (AIC $c_{c^{\prime}}$ Sugiura 1978). We used quadratic terms in order to model non-linear responses of species growth to various niche axes. We checked for homogeneity of variances (Bartlett test, visual inspection), normality of the residuals (Shapiro test, visual inspection) and influential points (Cook's distance). The initial biomass was ln-transformed and, depending on the species considered, from one to four influential points were detected and removed from the models investigated. These influential points corresponded to individuals having experienced a marked senescence between the two monitoring dates. The input variables were standardized to avoid collinearity between linear and quadratic terms and to estimate standardized beta coefficients to compare the effects of the explanatory variables with different units (Schielzeth 2010). Only the best model was presented, that corresponds to the most parsimonious model with both the lowest $\mathrm{AIC}_{\mathrm{c}}$ and with all explanatory variables being significant $(P<0.05$, according to a likelihood-ratio test based on the $\chi^{2}$ distribution). We determined both the marginal and the conditional $R^{2}\left(R_{\mathrm{m}}^{2}\right.$ and $\left.R_{\mathrm{c}}^{2}\right)$, that correspond to the variance explained by the fixed effects only and both the fixed and random effects, respectively (Nakagawa and Schielzeth 2013). We also assessed the effects of each environmental variable separately on RGR $_{\text {ind }}$ using simple linear and quadratic mixed models, and only the best model was presented (Supplementary Fig. S3). It should be noted that these analyses do not allow to evaluate the causal relationships of the environmental variables on the growth of each plant individual separately, the environmental variables being recorded at the site level while $\mathrm{RGR}_{\text {ind }}$ could also be affected by conditions at a finer scale.
Beyond the influence of environmental conditions on $\mathrm{RGR}_{\text {ind }}$ at the site level, we further partitioned the variance of $\mathrm{RGR}_{\text {ind }}$ and $\mathrm{RGR}_{\text {ind }}$ / SANPP within and between sites for each species separately. In doing so, we compared the relative importance of fine-scale variability and variability due to large-scale modifications of pedoclimatic conditions on intraspecific individual growth variability.

\section{Effect of species-averaged growth (dis-)advantage on species ranking at the community level}

We implemented a beta generalized linear mixed model (thereafter GLMM) to assess the effects of the species and the ratio $\mathrm{RGR}_{\text {spe }} / \mathrm{SANPP}$, i.e. the average $\mathrm{RGR}_{\text {ind }}$ /SANPP estimated at the species level within a site, on sSR, accounting for the site identity as random intercept and slope effects. The $\mathrm{RGR}_{\text {spe }}$ /SANPP can be considered as an estimation of the species-averaged growth (dis-)advantage relative to the whole community. We hypothesized that assembly mechanisms can differ between sites and therefore considered sites as a source of random variation on model intercept and slope effects. We used a beta GLMM because the response variable SSR is a continuous variable bounded between 0 and 1. For fixed effects, a likelihood-ratio test based on the $\chi^{2}$ distribution was used to evaluate the significance of the effect of the explanatory variables, and coefficients were given, with a $Z$ test used to evaluate their significance.

Statistical analyses were performed using R 3.6.2 (R Development Core Team 2019), its packages 'ade4' for PCA, 'Ime4' for LMMs, 'glmmTMB' for beta GLMMs and 'AICcmodavg' for model selection based on AIC . Metadata are described and a link to the datasets provided in Supplementary Material S4.

\section{RESULTS}

Effects of environmental conditions at the site level on plant growth at the individual level

The monitored environmental conditions recorded at the site level and the initial biomass of the individuals explained individual plant growth with variable accuracies (between $R_{\mathrm{m}}^{2}=0.18$ for $P$. pratensis and $R_{\mathrm{m}}^{2}=0.50$ for L. perenne; Table 1). We found that marginal relationships between environmental conditions were always monotonous, except for the relationship between the cumulative potential evapotranspiration and $\mathrm{RGR}_{\mathrm{ind}}$ of L. perenne and P. pratensis that were U-shaped (Table 1). Thus, the cumulative PAR available had an important effect on plant growth for three out of the four species, being always positively related to RGR at the individual level, especially for D. glomerata and L. perenne (Supplementary Fig. S3 and Supplementary Table S5). Moreover, the growth of these species was positively related to the cumulative rainfall, especially for $T$. repens, while the growth of $L$. perenne was negatively related to the cumulative potential evapotranspiration. The best model retained for $P$. pratensis showed a low $R_{\mathrm{m}}^{2}$ and did not highly differ from the intercept-only model ( $\mathrm{AIC}_{\mathrm{c}}-\mathrm{AIC}_{0}=4.79$ ), consequently the results for this species should be interpreted with caution (Supplementary Table S5). Still, the effects highlighted were consistent with the results of other species, P. pratensis presenting a higher growth in the most productive sites based on soil properties, and a lower growth in sites characterized by a high cumulative potential evapotranspiration (Table 1). Although the initial biomass was significantly negatively related to the $\mathrm{RGR}_{\text {ind }}$ for two species, it appeared highly influential only for D. glomerata.

\section{Relative importance of inter-individual variability of growth within and between sites}

We found that within-site variability of $\mathrm{RGR}_{\text {ind }}$ represents between $10.1 \%$ and $26.8 \%$ of the between-site variability (Table 2; Fig. 1). Furthermore, the mean squares of the within-site $\mathrm{RGR}_{\text {ind }} / \mathrm{SANPP}$, 
Table 1: Effect of the environmental variables recorded at the site level and the initial biomass at the individual level on the RGR at the individual level $\mathrm{RGR}_{\text {ind }}$, tested for each species separately based on the selection of the best LMM, accounting for the site identity as a random intercept factor

\begin{tabular}{|c|c|c|c|c|}
\hline & Dactylis glomerata & Lolium perenne & Poa pratensis & Trifolium repens \\
\hline Species & $(n=110)$ & $(n=112)$ & $(n=69)$ & $(n=106)$ \\
\hline Marginal $R^{2}$ & 0.42 & 0.50 & 0.18 & 0.23 \\
\hline Conditional $R^{2}$ & 0.45 & 0.56 & 0.18 & 0.42 \\
\hline $\mathrm{AIC}_{\mathrm{c}}-\mathrm{AIC}_{0}$ & 27.49 & 19.68 & 4.79 & 4.60 \\
\hline \multicolumn{5}{|l|}{ Fixed effects } \\
\hline Intercept & $-0.32 * *$ & $-0.38 * *$ & $-0.34 *$ & 0.02 n.s. \\
\hline Initial biomass & $-0.30 * * *$ & -0.24 ** & & \\
\hline Soil PC1 & & & $0.36^{* *}$ & \\
\hline \multicolumn{5}{|l|}{ Soil $\mathrm{PCl}^{2}$} \\
\hline $\mathrm{P}_{\text {cumul }}$ & $0.15\left(^{*}\right)$ & $0.32 * *$ & & $0.37 * *$ \\
\hline $\mathrm{P}_{\text {cumul }}^{\text {cumul }} 2$ & $0.33 * * *$ & & & \\
\hline $\mathrm{PET}_{\text {cumul }}$ & & $-0.38^{* * *}$ & $-0.41^{* *}$ & \\
\hline $\mathrm{PET}_{\text {cumul }}^{2}$ & & $0.37 * * *$ & $0.34 * *$ & \\
\hline PAR $_{\text {cumul }}$ & $0.57 * * *$ & $0.42 * * *$ & & $0.35^{* *}$ \\
\hline \multicolumn{5}{|c|}{$\mathrm{PAR}_{\text {cumul }}^{2}$} \\
\hline \multicolumn{5}{|c|}{ Random effect—site identity } \\
\hline Intercept & 0.172 & 0.237 & 0.000 & 0.441 \\
\hline
\end{tabular}

The standardized beta coefficients of the selected explanatory variables and their associated $P$-values based on $\chi^{2}$ distributions are reported. The selected models were the most parsimonious model with both the lowest $\mathrm{AIC}_{\mathrm{c}}$ and with all explanatory variables being significant. AIC ${ }_{\mathrm{c}}-\mathrm{AIC}_{0} \mathrm{corresponds}$ to the difference of AIC between the best model and the intercept-only model including the random intercept factor (standard-deviation). Marginal and conditional $R^{2}$ correspond to the variance explained by the fixed effects only $\left(R_{\mathrm{m}}^{2}\right)$ and both the fixed and random effects $\left(R_{\mathrm{c}}^{2}\right)$ were given. n.s., not significant. $n$ corresponds to the number of individuals. See Supplementary Table S5 for more detailed results.

(*) $P$-value $<0.1, * P$-value $<0.05, * * P$-value $<0.01, * * * P$-value $<0.001$.

Table 2: Inter-individual variability of individual growth ( $\mathrm{RGR}_{\text {ind }}$ ) and individual growth (dis-)advantage relative to the whole community (RGR ind $_{\text {SANPP) }}$ computed as the mean squares within and between sites ( $m e a n \mathrm{sq}_{\text {within }}$ and mean $\mathrm{sq}_{\text {between }}$, respectively), for each species separately

\begin{tabular}{|c|c|c|c|c|}
\hline & \multicolumn{2}{|l|}{$\mathrm{RGR}_{\text {ind }}$} & \multicolumn{2}{|c|}{$\mathrm{RGR}_{\text {ind }} / \mathrm{SANPP}$} \\
\hline & Mean $\mathrm{sq}_{\text {within }}$ & Mean $\mathrm{sq}_{\text {between }}$ & Mean $\mathrm{sq}_{\text {within }}$ & Mean $\mathrm{sq}_{\text {between }}$ \\
\hline Dactylis glomerata & $2.02 \times 10^{-7}$ & $9.26 \times 10^{-7}$ & 0.23 & 1.14 \\
\hline Lolium perenne & $2.98 \times 10^{-7}$ & $2.96 \times 10^{-6}$ & 0.61 & 1.98 \\
\hline Poa pratensis & $1.99 \times 10^{-7}$ & $7.43 \times 10^{-7}$ & 0.15 & 0.30 \\
\hline Trifolium repens & $3.54 \times 10^{-7}$ & $2.34 \times 10^{-6}$ & 0.89 & 1.04 \\
\hline
\end{tabular}

indicative of the individual growth (dis-)advantage compared with the whole vegetation, accounted for $20.2-85.6 \%$ of the between-site variability (Table 2). Even if this set of species represents a small number of the co-occurring vascular plant species of the 18 local communities studied, we found that within-species site-averaged variability of individual growth represented a moderate to high between-species site-averaged variability, even higher within- than between-species in several sites (Supplementary Material S6).

\section{Effect of species-averaged growth (dis-)advantage on species ranking at the community level}

Species ranking (sSR) was significantly explained by the species identity $\left(\chi^{2}=407.55, P<0.001\right)$ but not by the species-averaged individual growth relative to the whole community $\mathrm{RGR}_{\text {spe }}$ SSANPP $\left(\chi^{2}=1.59\right.$, $P=0.21 ; \mathrm{RGR}_{\text {ind }} /$ SANPP presented in Fig. 2$)$, with each species being explanatory of SSR (Table 3).

\section{DISCUSSION}

We studied plant individual growth of four common species of temperate permanent grasslands, its response to environmental conditions at the site level, its intraspecific variability within and between sites and its influence on species ranking at the community level. To do so, we studied multiple sites covering a large pedoclimatic gradient and various production situations. Using a recent non-destructive method developed to characterize the growth of individual plants in grasslands, we highlighted that environmental conditions at the site level explain a significant proportion of individual growth variability for three out of the four species studied, the main explanatory environmental conditions being different between species. Moreover, we highlighted a moderate to high within-site inter-individual variability of growth. Finally, we found that interspecific differences of species-averaged individual growth relative to its reference community did not affect species ranking at the community level.

Regarding the influence of environmental conditions on plant individual RGR, light availability and the amount of accumulated rainfall over the period of study showed positive effects for some species. This is in accordance with previous studies carried out under controlled conditions (Galmés et al. 2005; Hofmann and Isselstein 2004). Unexpectedly, soil properties, among which the total nitrogen pool in the upper soil layer, had only a slight effect on plant individual RGR, which contrast with previous findings (Glimskär and Ericsson 1999; Meziane and Shipley 1999). We further found a negative relationship 

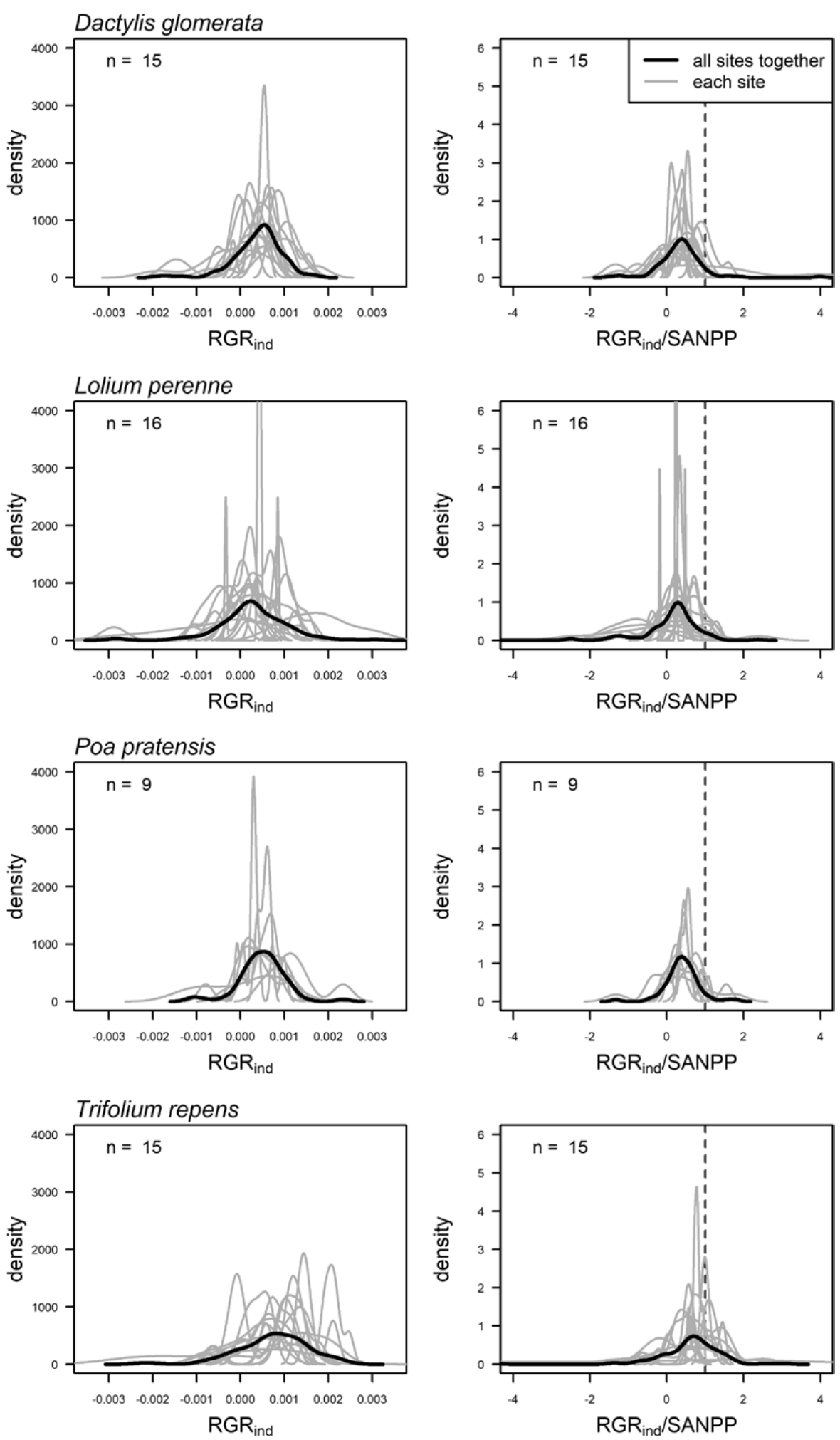

Figure 1: Distribution of individual growth $\left(\mathrm{RGR}_{\text {ind }}\right.$ ) and growth (dis-)advantage of individuals relative to the whole community (RGR ind $\left./ \mathrm{SANPP}\right)$ within and between sites for each species. $\mathrm{n}$ corresponds to the number of sites where the species were monitored $($ maximum $=18)$.

between RGR and initial biomass at the individual, in accordance with previous studies (Rees et al. 2010; Rose et al. 2009). This confirms the need to account for the initial biomass as a concomitant factor, since RGR, as measurements of intrinsic growth, typically decreases as individuals get larger, especially due to leaf senescence and increase in maintenance costs during the plant development.

The largest part of RGR variations remained unexplained by the environmental conditions at the site level. This may partly be due to 

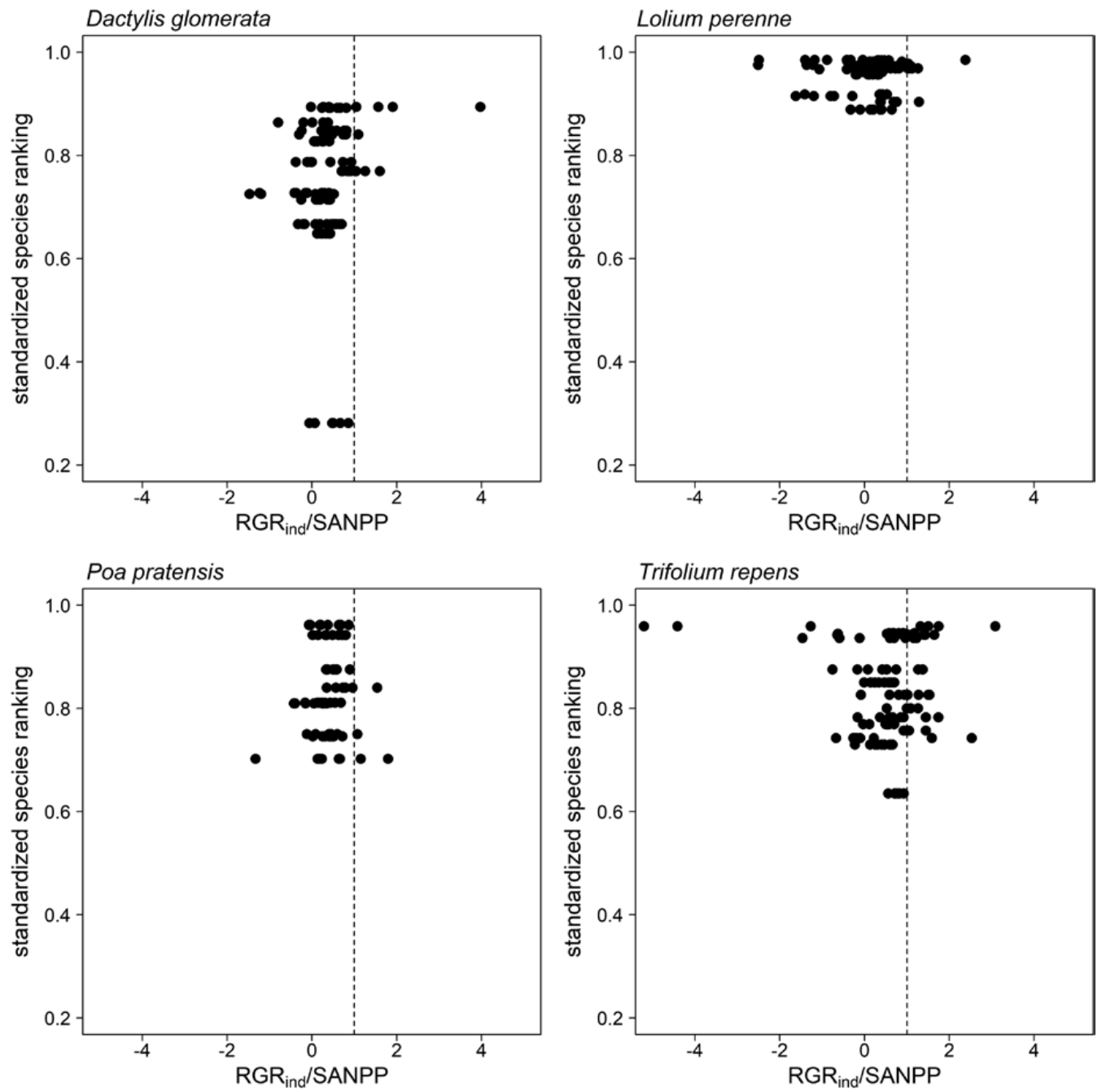

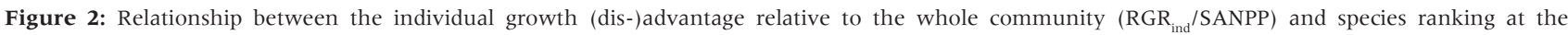
community level (standardized species ranking based on occurrence frequency, sSR) for each species separately.

an insufficient characterization of driving environmental variables. We characterized most of the key soil properties and meteorological variables known to directly influence growth, and potentially the nature and intensity of plant interactions (Bertness and Callaway 1994; Maestre et al. 2009). However, part of RGR variations might be explained by more proximal biotic factors and site description of disturbance regimes, for instance the potential herbivory pressure (Rose et al. 2009). Another explanation is related to the moderate to high within-site intraspecific variability in plant growth, comprised between $10.1 \%$ and $26.8 \%$ of the observed between-site variability when considering $\mathrm{RGR}_{\text {ind }}$ and between $20.2 \%$ and $85.6 \%$ when considering $\mathrm{RGR}_{\text {ind }} / \mathrm{SANPP}$, i.e. the individual growth (dis-)advantage relative to the whole community. These results are particularly striking since we studied a large pedoclimatic gradient that should inflate between-site compared with within-site variability. We suggest that within-site intraspecific variability may have two sources. First, this variability may be due to intrinsic plant variability, notably related to interindividual variations in reserve amounts that is recognized to influence plant growth (Gleeson and Tilman 1994; Turnbull et al. 2008). Second this variability may be due to within-site environmental heterogeneity. Indeed, plant resources and disturbance, and thus growth conditions, are well-known to be highly heterogeneous within grasslands (Bloor and Pottier 2014). In addition, competition occurs at the plant neighbourhood scale (Purves and Law 2002), exacerbating differences between focal individuals of a same species (e.g. Trinder et al. 2013). Future analyses of within-site intraspecific variability of growth should therefore characterize the local environmental conditions experienced by focal individuals and use direct measurements to characterize the 'plant's eye view' of biotic interactions.

Our study also evidenced that better growth at the individual level, estimated using species-averaged individual growth, did not scale-up to higher species ranking at the community level, while species ranking was largely explained by the species identity. This result is in line with McGill et al. (2006) who considered that fast growth potential might not be a good proxy of species ranking, and Reader (1998) who reported, in a resource-poor habitat, that growth was negatively related to the species occurrence frequency. In our particular context, we suggest two possible explanations for this lack of relationship between growth and species ranking. First, growth may not be the main determinant of species performance at the community level. In disturbance-prone ecosystems such as permanent grasslands, regenerative processes appear crucial to persist and grow. Consequently, regenerative strategies of species may play a key role in community patterning (Larson and Funk 2016), especially clonality (Benson and Hartnett 2006; Vojtko et al. 2017). A second possible explanation is that the high inter-individual within-site growth variability could blur interspecific 
Table 3: Effect of the species identity and $\mathrm{RGR}_{\text {spe }} / \mathrm{SANPP}$ on sSR based on beta GLMM, accounting for the field identity as random intercept and slope effects

Beta GLMM: sSR $\sim \mathrm{RGR}_{\text {ind }} / \mathrm{SANPP}+$

species $+\left(\mathrm{RGR}_{\text {ind }} / \mathrm{SANPPIsite}\right)$

\begin{tabular}{|c|c|c|}
\hline Fixed effect & df & $\chi^{2}(P$-value $)$ \\
\hline Intercept & 1 & $108.52^{* * *}$ \\
\hline $\mathrm{RGR}_{\text {ind }} / \mathrm{SANPP}$ & 1 & 1.59n.s. \\
\hline \multirow[t]{2}{*}{ Species } & 3 & $407.55^{* * *}$ \\
\hline & $\begin{array}{l}\text { Coefficient } \\
\text { (standard error) }\end{array}$ & $Z$ (P-value) \\
\hline $\begin{array}{l}\text { Intercept (reference species: } \\
\text { Dactylis glomerata) }\end{array}$ & $1.161(0.111)$ & $10.47 * * *$ \\
\hline $\mathrm{RGR}_{\text {ind }} / \mathrm{SANPP}$ & $-0.133(0.105)$ & $-1.26 \mathrm{n} . \mathrm{s}$. \\
\hline Lolium perenne & $1.929(0.096)$ & $20.09 * * *$ \\
\hline Poa pratensis & $0.435(0.089)$ & 4.91 *** \\
\hline Trifolium repens & $0.686(0.079)$ & $8.65^{* * *}$ \\
\hline Random effect-site identity & Variance & $\begin{array}{l}\text { Standard } \\
\text { deviation }\end{array}$ \\
\hline Intercept & 0.155 & 0.394 \\
\hline $\mathrm{RGR}_{\text {ind }} / \mathrm{SANPP}$ & 0.091 & 0.301 \\
\hline
\end{tabular}

For fixed effects, a likelihood-ratio test based on the $\chi^{2}$ distribution was used to evaluate the significance of the effect of the explanatory variables (type II analysis of deviance), and coefficients were given with a $Z$ test used to evaluate their significance. n.s., not significant. $* * * P$-value $<0.001$

differences in competitive abilities. Indeed, a high inter-individual variability has been shown to promote coexistence of species even with large differences in competitive abilities when environmental conditions are spatially structured at fine scale (Uriarte and Menge 2018).

In addition to these basic explanations relying on the processes shaping community assembly, several methodological limitations of our study may also contribute to our findings. First, our study, as any multisite analyses based on data collected in a single year, neglect the role of historical contingency, with past events likely to have long lasting impacts on community patterns (Fukami 2015; Piqueray et al. 2011 ) but not necessarily on the short-term seasonal growth of plant individuals. The grasslands have been sown for at least 20 years, so we could hypothesized that the ranking of species within the community is at least partly the result of mid- to long-term trends while RGR could be more influenced by between-year variability in weather conditions and resource availability. Second, we chose to assess species ranking at the community level using frequency data. Although this approach is relevant and widely applied, frequency data may lead to different patterns of species abundance compared with biomass data (Lepš et al. 2006). Third, our monitoring of plant growth and environmental conditions have required the use of exclosure plots to avoid evaluating the effect of local management. Our choice led to modify the light penetration through the canopy compared with standard herbage use characterizing these permanents grasslands for at least 20 years, i.e. grazing or/and mowing with reopening of the canopy over the growing season (Supplementary Fig. S7). Since the cumulative PAR available was the most explanatory driver of RGR for most species, it is likely that plant growth at the individual level during the monitoring period did not necessarily adequately represent the normal growth rates of the four species under standard management conditions.

\section{CONCLUSIONS}

Considering temperate permanent grasslands distributed along a large pedoclimatic gradient, we first highlighted that environmental conditions explained a significant but variable proportion of the individual growth variability for four typical species of this type of grassland. In particular, light availability was the main driver of individual plant growth, especially for D. glomerata and L. perenne, followed by rainfall amount, especially for T. repens, and potential evapotranspiration, while soil properties had only a slight effect. We then found that the within-site variability of plant individual growth was relatively high compared with the between-site variability despite the large pedoclimatic gradient studied. We finally showed that greater species-averaged individual growth compared with the whole community did not result to better ranking at the community level for these four species. Thanks to the non-destructive method used for estimating aboveground biomass, we were able to demonstrate, for the first time in temperate grassland communities, that individual growth is highly variable among individuals of the same species in the same site. This finding opens up novel perspectives for future research.

\section{Supplementary Material}

Supplementary material is available at Journal of Plant Ecology online. Table S1: Environmental properties of the 18 sites studied, including soil and meteorological variables

Figure S1: Standardized principal component analysis (PCA) on the set of soil variables for the 18 sites.

Figure S2: Relationship between the estimated aboveground biomass using the allometric general equation and the estimated biomass using species-specific best equation for twelve species with varying architectures based on the dataset of Pottier and Jabot (2017).

Figure S3: Inter-individual variability of RGR at the individual level $\mathrm{RGR}_{\text {ind }}$ along the soil gradient (soil PC1) and some resource availability gradients $\left(\mathrm{P}_{\text {cumul' }}, \mathrm{PET}_{\text {cumul' }}, \mathrm{PAR}_{\text {cumul }}\right.$ refer to the main text for details).

Material S4: Metadata description of three datasets: FLORIS_botanical_ survey_2017.csv, FLORIS_environmental_conditions_2017.csv and FLORIS_RGR_individual_level_2017.csv; and link to the datasets. Table S5: Effect of the environmental variables recorded at the site level and the initial biomass at the individual level on the relative growth rate at the individual level $\mathrm{RGR}_{\text {ind }}$ tested for each species separately based on LMM, accounting for the field identity as a random intercept effect.

Material S6: Inter-individual variability of individual growth within and between species for each site.

Figure S7: Cumulative rainfall $\left(\mathrm{P}_{\text {cumul }}\right)$, cumulative potential evapotranspiration $\left(\mathrm{PET}_{\text {cumul }}\right)$ and cumulative PAR available $\left(\mathrm{PAR}_{\text {cumul }}\right)$ over the same period in terms of GDD, i.e. between $550 \pm 40$ and $1350 \pm 90$ GDD during the year of the study (year 2017) and based on climate normals.

\section{Funding}

This work was supported by the Region Auvergne-Rhône-Alpes and the European Regional Development Fund (FEDER) (grant no. AV0008781)

\section{Acknowledgements}

We would like to thank the farmers for their participation, and G. Benquey for her help in the field. This work was supported by The French government IDEX-ISITE initiative 16-IDEX-0001 (CAP 20-25). 
We are grateful to the editor and two anonymous reviewers who helped improving the manuscript.

Conflict of interest statement. None declared.

\section{REFERENCES}

Aarssen LW, Turkington R (1985) Biotic specialization between neighbouring genotypes in Lolium perenne and Trifolium repens from a permanent pasture. $J$ Ecol 73:605-14.

Albert CH, Thuiller W, Yoccoz NG, et al. (2010) Intraspecific functional variability: extent, structure and sources of variation. J Ecol 98:604-13.

Altesor A, Leoni E, Guido A, et al. (2017) Differential responses of three grasses to defoliation, water and light availability. Plant Ecol 218:95-104.

Antonetti P, Brugel E, Kessler F, et al. (2006) Atlas de la Flore d'Auvergne. ChavaniacLafayette, France: Conservatoire botanique national du Massif Central.

Benson EJ, Hartnett DC (2006) The role of seed and vegetative reproduction in plant recruitment and demography in tallgrass prairie. Plant Ecol 187:163-78.

Bertness MD, Callaway R (1994) Positive interactions in communities. Trends Ecol Evol 9:191-3.

Biere A (1996) Intra-specific variation in relative growth rate: impact on competitive ability and performance of Lychnis flos-cuculi in habitats differing in soil fertility. Plant Soil 182:313-27.

Bloor JM, Pottier J (2014) Grazing and spatial heterogeneity: implications for grassland structure and function. In Mariotte P, Kardol P (eds). Grassland Biodiversity and Conservation in a Changing World. New York, NY: Nova Science Publishers, 135-62.

Dormann CF, Elith J, Bacher S, et al. (2013) Collinearity: a review of methods to deal with it and a simulation study evaluating their performance. Ecography 36:27-46.

Epp GA, Aarssen LW (1989) Predicting vegetation patterns from attributes of plant growth in grassland species. Can J Bot 67:2953-59.

Fridley JD, Grime JP, Bilton M (2007) Genetic identity of interspecific neighbours mediates plant responses to competition and environmental variation in a species-rich grassland. $J$ Ecol 95:908-15.

Fukami T (2015) Historical contingency in community assembly: integrating niches, species pools, and priority effects. Annu Rev Ecol Evol Syst 46:1-23.

Galmés J, Cifre J, Medrano H, et al. (2005) Modulation of relative growth rate and its components by water stress in Mediterranean species with different growth forms. Oecologia 145:21-31.

Garnier E, Cortez J, Billès G, et al. (2004) Plant functional markers capture ecosystem properties during secondary succession. Ecology 85:2630-7.

Gleeson SK, Tilman D (1994) Plant allocation, growth rate and successional status. Funct Ecol 8:543-50.

Glimskär A, Ericsson TOM (1999) Relative nitrogen limitation at steady-state nutrition as a determinant of plasticity in five grassland plant species. Ann Bot 84:413-20.

Grime JP (1977) Evidence for the existence of three primary strategies in plants and its relevance to ecological and evolutionary theory. Am Nat 111:1169-94.

Hargreaves GH, Samani ZA (1985) Reference crop evapotranspiration from temperature. Appl Eng Agric 1:96-9.

Hart SP, Schreiber SJ, Levine JM (2016) How variation between individuals affects species coexistence. Ecol Lett 19:825-38

Hofmann M, Isselstein J (2004) Effects of drought and competition by a ryegrass sward on the seedling growth of a range of grassland species. J Agron Crop Sci 190:277-86.

Larson JE, Funk JL (2016) Regeneration: an overlooked aspect of trait-based plant community assembly models. $J$ Ecol 104:1284-98.

Leibold MA, Holyoak M, Mouquet N, et al. (2004) The metacommunity concept: a framework for multi-scale community ecology. Ecol Lett 7:601-13.

Lepš J, de Bello F, Lavorel S, et al. (2006) Quantifying and interpreting functional diversity of natural communities: practical considerations matter. Preslia 78:581-601.

Maestre FT, Callaway RM, Valladares F, et al. (2009) Refining the stress-gradient hypothesis for competition and facilitation in plant communities. $J$ Ecol 97:199-205.
McGill BJ, Enquist BJ, Weiher E, et al. (2006) Rebuilding community ecology from functional traits. Trends Ecol Evol 21:178-85.

McMaster GS, Wilhelm WW (1997) Growing degree-days: one equation, two interpretations. Agric For Meteorol 87:291-300.

Meziane D, Shipley B (1999) Interacting components of interspecific relative growth rate: constancy and change under differing conditions of light and nutrient supply. Funct Ecol 13:611-22.

Nakagawa S, Schielzeth H (2013) A general and simple method for obtaining $R^{2}$ from generalized linear mixed-effects models. Methods Ecol Evol 4:133-42.

Perronne R, Amiaud B, Benquey G, et al. (2019) Quelle pertinence du modèle diversité-productivité-perturbations pour analyser l'influence des pratiques agricoles sur la diversité des prairies permanentes du Massif central? Fourrages 237:47-55.

Pielou EC (1966) Species-diversity and pattern-diversity in the study of ecological succession. J Theor Biol 10:370-83.

Piqueray J, Cristofoli S, Bisteau E, et al. (2011) Testing coexistence of extinction debt and colonization credit in fragmented calcareous grasslands with complex historical dynamics. Landsc Ecol 26:823-36.

Pottier J, Jabot F (2017) Non-destructive biomass estimation of herbaceous plant individuals: a transferable method between contrasted environments. Eco Indic 72:769-76.

Purves DW, Law R (2002) Fine-scale spatial structure in a grassland community: quantifying the plant's-eye view. $J$ Ecol 90:121-9.

R Development Core Team (2019) R: A Language and Environment for Statistical Computing. Vienna, Austria: R Foundation for Statistical Computing. https:// www.r-project.org/ (29 April 2020, date last accessed).

Reader RJ (1998) Relationship between species relative abundance and plant traits for an infertile habitat. Plant Ecol 134:43-51.

Rees M, Osborne CP, Woodward FI, et al. (2010) Partitioning the components of relative growth rate: how important is plant size variation? Am Nat 176:E152-61.

Reich PB (2014) The world-wide 'fast-slow' plant economics spectrum: a traits manifesto. J Ecol 102:275-301.

Roscher C, Scherer-Lorenzen M, Schumacher J, et al. (2011) Plant resource-use characteristics as predictors for species contribution to community biomass in experimental grasslands. Perspect Plant Ecol Syst 13:1-13.

Rose KE, Atkinson RL, Turnbull LA, et al. (2009) The costs and benefits of fast living. Ecol Lett 12:1379-84

Schielzeth H (2010) Simple means to improve the interpretability of regression coefficients. Methods Ecol Evol 1:103-13.

Shipley B, Vile D, Garnier E (2006) From plant traits to plant communities: a statistical mechanistic approach to biodiversity. Science 314:812-4.

Siefert A, Violle C, Chalmandrier L, et al. (2015) A global meta-analysis of the relative extent of intraspecific trait variation in plant communities. Ecol Let 18:1406-19.

Sugiura N (1978) Further analysts of the data by Akaike's information criterion and the finite corrections: further analysts of the data by Akaike's. Commun Stat Theory Methods 7:13-26.

Tilman D (1988) Plant Strategies and the Dynamics and Structure of Plant Communities. Princeton, NJ: Princeton University Press.

Trinder CJ, Brooker RW, Robinson D (2013) Plant ecology's guilty little secret: understanding the dynamics of plant competition. Funct Ecol 27:918-29.

Turcotte MM, Levine JM (2016) Phenotypic plasticity and species coexistence. Trends Ecol Evol 31:803-13.

Turnbull LA, Paul-Victor C, Schmid B, et al. (2008) Growth rates, seed size, and physiology: do small-seeded species really grow faster? Ecology $\mathbf{8 9}$ 1352-63.

Uriarte M, Menge D (2018) Variation between individuals fosters regional species coexistence. Ecol Lett 21:1496-504.

Violle C, Navas ML, Vile D, et al. (2007) Let the concept of trait be functional! Oikos 116:882-92.

Vojtko AE, Freitag M, Bricca A, et al. (2017) Clonal vs leaf-height-seed (LHS) traits: which are filtered more strongly across habitats? Folia Geobot $\mathbf{5 2}$ 269-81. 